AUDIT

\title{
KNOWLEDGE AND COMPLIANCE WITH REGARD TO UNIVERSAL PRECAUTIONS AND OTHER STANDARD PRACTICES TO REDUCE BLOOD-BORNE INFECTIONS AMONG ANAESTHETISTS AT THE NATIONAL HOSPITAL OF SRI LANKA
}

\author{
W. A. Tharanga, P. Perera* \\ Senior Registrar in Anaesthesiology, National Hospital of Sri Lanka \\ "Corresponding author Email: tharangape@gmail.com
}

Key words: risk of transmission, blood-borne infections, universal precautions, experience, gender, wearing of gloves

\begin{abstract}
Anaesthetists are a group of doctors who are at a higher occupational risk of contracting blood borne infections as they perform many invasive procedures. Practice of Universal Precautions (UP) is vital in reducing the risk of transmission. The objective of this study was to assess the knowledge and compliance among anaesthetists of the National Hospital of Sri Lanka (NHSL) on UP and related issues. Information was collected from 97 anaesthetists at the NHSL using a structured questionnaire. Knowledge and practice of UP was assessed separately through specific questions. The average percentage mark of the 97 respondents on their knowledge on UP was $77.43 \%$ with a standard deviation of 13.84 . Approximately, $68 \%$ of the respondents obtained above-average marks. With regard to practise of UP, $61 \%$ of the respondents had their total coded mark within the range from 14 to 16 out of the possible maximum of 21 . There was no significant correlation between knowledge and practice. Only $15 \%$ of the population wore gloves during all procedures at OT, and $46 \%$ has stated that it is comfortable to work without gloves as the reason for not wearing. Based on these results, it is concluded that there is appreciable room for improvement of knowledge and practice of UP among anaesthetists. The study further revealed that knowledge and practice of UP is not related to gender or experience, which indicated that it is probably a personal trait of each respondent, depending on the discipline and application of each individual.
\end{abstract}

\section{Introduction}

Anaesthetists are at a higher risk in getting accidental needle stick injuries ${ }^{1}$, when compared to other doctors as they are frequently involved with critically ill patients and perform venepuncture, insertion of arterial lines, CV catheters, vascaths for renal replacement etc.. It is critical that they have the knowledge to minimize the risk of transmission, by following Universal Precautions (UP) and other standard practices, like proper handling and disposal of sharps.
Prevalence of HIV is advancing both worldwide and in Sri Lanka. According to the 2009

statistics, people living with HIV are estimated to be 33 million worldwide, making it more common to encounter them in our clinical practice. UP are the basic steps recommended to prevent blood-borne infections among health care workers, which include barrier precautions such as wearing non-porous gloves, aprons, masks, eye protectors and hand washing. Under UP blood and certain body fluids (semen, vaginal secretions, CSF, amniotic, peritoneal, 
pleural, pericardial and synovial fluids) of all patients are considered potentially infectious. UP does not routinely apply for faeces, nasal secretions, saliva, sweat, tears, urine and vomitus unless blood stained. It is recommended to change gloves after contact of each patient or when they are contaminated. Hands and other skin surfaces need to be washed as soon as practical if contacted with body fluids requiring UP, and also after removing gloves. Contaminated needles should never be recapped or removed from disposable syringes, and need to be discarded into puncture resistant container placed, as close as practical to the user area.

UP was initially developed in 1987 by the Centres for the Disease Control and prevention (CDC) in United States. In 1996 the concept was expanded to standard precautions which included disinfection of clinical environment, sterile disposables, scrubbing and proper disposal of sharps in addition to basic $\mathrm{UP}^{2,3}$. The risk of transmission of Hep $\mathrm{B}$ can be entirely eliminated by having an adequate immune coverage. It is safer to obtain even during pregnancy ${ }^{4}$. Acquired immune status should be tested 1-2 months after completion of the three dose vaccine series. The annual number of occupational infections of HBV has reduced by $95 \%$ since Hep B vaccine became available in $1982(>10,000$ in 1983 and $<400$ in 2001) $)^{4}$.

It is important to practice UP on all patients as there is a general tendency to take precautions only when handling suspected or already diagnosed patients of having such infections. The prime reason for undertaking this study was that most of the patients living with HIV cannot be suspected by their appearance or the general wellbeing. They appeared to be normal and healthy-looking people of variable socio economic backgrounds. Therefore it is important to practice UP on all the patients. There are National Guidelines on Standard Precautions developed by The Sri Lanka College of Microbiologists (SLCM), which describe work practices needed to be adopted by healthcare workers to minimize the occupational risk of contracting blood borne infections. Although the guidelines are intended to be used by all the institutions under the Ministry of Health, they are not widely available for reference. Hence, the specific objectives of this study were: (a) To describe knowledge among anaesthetists on Universal Precautions and related issues; (b) To describe compliance with UP; (c) To determine the association between knowledge and practice of UP.

\section{Methodology \\ Study population}

All anaesthetists including trainees who came for duty at NHSL during the month of April 2008 were included. A structured questionnaire was distributed among 100 anaesthetists, either at the operating theatres or at the switch board and was collected personally and confidentially. 97 anaesthetists responded. Table 1 describes the study population in terms of gender and experience as anaesthetists.

Table 1: Description of the study population in terms of gender and experience.

\begin{tabular}{|l|l|c|}
\hline Gender & Experience (Years) & No. of Respondents \\
\hline Male & $<6$ months & 1 \\
\hline & 6 months -5 years & 14 \\
\hline & $>5$ years & 21 \\
\hline & Sub-total & 36 \\
\hline Female & $<6$ months & 1 \\
\hline & 6 months -5 years & 24 \\
\hline & $>5$ years & 36 \\
\hline & Sub-total & 61 \\
\hline & Total & 97 \\
\hline
\end{tabular}

\section{Assessments}

The questionnaire (Appendix I) was structured to obtain information regarding:

$>$ Knowledge on risk of transmission of bloodborne infections

$>$ Knowledge on UP

$>$ Practice of UP

$>$ Any restrictions and limitations for the practice of UP

$>$ Knowledge on the management of an accidental needle stick injury

$>$ Status of immunity of the respondents against $\mathrm{HBV}$

$>$ Attendance of any form of educational programme on UP

$>$ Experience as anaesthetists and gender 


\section{Data analysis}

Knowledge of UP was assessed as the percentage total mark for correct answers to relevant questions. Each correct response was given 1 mark while each incorrect response was given a -1 mark. There were only two unmarked responses, which were given zero marks. The total number of responses was 18 and therefore an overall mark out of 18 , was given to each respondent which was subsequently converted to a percentage.

Practice of UP was assessed by coding the practices in such a way that the best practices received the highest coded score and totalling the coded score (Appendix II). For the questions related to practice of UP, the respondents were evaluated by giving coded marks for each practice and giving a total coded mark for each respondent. A higher coded mark was given for 'good' practices while a lower coded mark was given for 'bad' practices. Therefore, a respondent with a higher total coded mark is one who practices UP to a large extent and vice versa.

Table 2: Frequency distribution of the percentage mark for knowledge on UP

\begin{tabular}{|l|c|c|}
\hline Marks Range (\%) & No. of Respondents & $\%$ in the Population \\
\hline$<0$ & 2 & 2.06 \\
\hline $0-9$ & 6 & 6.19 \\
\hline $10-19$ & 4 & 4.12 \\
\hline $20-29$ & 2 & 2.06 \\
\hline $30-39$ & 6 & 6.19 \\
\hline $40-49$ & 11 & 11.34 \\
\hline $50-59$ & 19 & 19.59 \\
\hline $60-69$ & 22 & 22.68 \\
\hline $70-79$ & 15 & 15.46 \\
\hline $80-89$ & 7 & 7.22 \\
\hline$>90$ & 3 & 3.09 \\
\hline
\end{tabular}

\section{Results and Discussion \\ Knowledge on UP}

Frequency distribution of the percentage marks for knowledge on UP is shown in Table 2. The average percentage mark of the 97 respondents was $54.87 \%$ with a standard deviation of 27.68 . Approximately, $68 \%$ of the respondents obtained above average marks for questions on
UP. Just above $10 \%$ of the respondents scored over $90 \%$ while just above $12 \%$ of the respondents scored less than 20\%. About 58\% of respondents had marks between $50 \%$ and $79 \%$. Based on the above results, it can be concluded that while the knowledge on UP among the anaesthetists need substantial improvement as the average mark is only $54.87 \%$. This is particularly so in view of the fact that only $10 \%$ of anaesthetists who responded to the present study could score over $90 \%$ in the test on knowledge.

Table 3: Variation of knowledge on UP with gender and experience of the respondents

\begin{tabular}{|l|l|c|c|c|}
\hline & Gender & $\begin{array}{c}\text { No. of } \\
\text { Respondents }\end{array}$ & $\begin{array}{c}\text { Mean } \\
\text { Mark } \\
(\%)\end{array}$ & $\begin{array}{c}\text { Standard } \\
\text { Deviation }\end{array}$ \\
\hline Male & $<6$ months & 1 & 66.67 & - \\
\hline & $\begin{array}{l}6 \quad \text { months - 5 } \\
\text { years }\end{array}$ & 14 & 53.97 & 26.10 \\
\hline & $>5$ years & 21 & 50.26 & 26.44 \\
\hline & Sub-total/Mean & 36 & 52.16 & 25.73 \\
\hline Female & $<6$ months & 1 & 77.78 & - \\
\hline & $\begin{array}{l}6 \text { months - 5 } \\
\text { years }\end{array}$ & 24 & 55.56 & 24.52 \\
\hline & $>5$ years & 36 & 56.48 & 31.91 \\
\hline & Sub-total/Mean & 61 & 56.47 & 28.85 \\
\hline & Total/Mean & 97 & 54.87 & 27.68 \\
\hline
\end{tabular}

Variation of knowledge on UP with gender and experience

Variation of percentage marks for knowledge on UP between the two gender groups and between different experience groups is shown in Table 3. The average mark scored by female respondents was slightly higher than that scored by their male counterparts. However, analysis of variance (ANOVA) showed that this difference was not statistically significant at $\mathrm{p}=0.05$. Interestingly, within both gender groups, the two respondents with less than 6 months of experience scored higher marks than their more experienced colleagues. However, this result cannot be generalized as there was only one respondent in the $<6$ month experience group. Furthermore, ANOVA of the data of this study showed that the percentage mark obtained did not vary significantly with experience. 
Therefore, based on the above results, it can be concluded that knowledge on UP is not related to gender or experience. It is probably a personal trait of each respondent, irrespective of their gender or experience.

Table 4: Frequency distribution of the total coded mark for practicing UP by the respondents

\begin{tabular}{|c|c|c|}
\hline $\begin{array}{c}\text { Total coded mark } \\
\text { obtained }\end{array}$ & $\begin{array}{c}\text { No. of } \\
\text { Respondents }\end{array}$ & \% in the Population \\
\hline 11 & 2 & 2.06 \\
\hline 12 & 6 & 6.19 \\
\hline 13 & 8 & 8.25 \\
\hline 14 & 21 & 21.65 \\
\hline 15 & 17 & 17.53 \\
\hline 16 & 21 & 21.65 \\
\hline 17 & 12 & 12.37 \\
\hline 18 & 4 & 4.12 \\
\hline 19 & 3 & 3.09 \\
\hline 20 & 1 & 1.03 \\
\hline 21 & 2 & 2.06 \\
\hline
\end{tabular}

†Maximum possible coded mark is 21 .

\section{Variation of practice of $U P$}

Frequency distribution of the total coded marks obtained for practice of UP by the 97 respondents is given in Table 4. About $61 \%$ of the respondents had their total coded mark within the range from 14 to 16 out of the possible maximum of 21 . About $6 \%$ of the respondents had 19 or more total coded marks with 2 respondents obtaining the maximum possible 21 . On the other hand, $16 \%$ of the respondents had total coded marks of 13 or less. Here again, the conclusion based on these results is that there is appreciable room for improvement in the practice of UP among the anaesthetists.

Table 5: Frequency distributions of the total coded marks for practice of UP among male and female respondents

\begin{tabular}{|c|c|c|c|c|}
\hline \multirow{2}{*}{$\begin{array}{c}\text { Total } \\
\text { coded } \\
\text { mark } \\
\text { obtained }\end{array}$} & $\begin{array}{c}\text { No. of } \\
\text { Respondent } \\
\text { s }\end{array}$ & $\begin{array}{c}\text { \% in the } \\
\text { Population }\end{array}$ & $\begin{array}{c}\text { No. of } \\
\text { Responde } \\
\text { nts }\end{array}$ & $\begin{array}{c}\% \text { in } \\
\text { the } \\
\text { Popul } \\
\text { ation }\end{array}$ \\
\hline 11 & 1 & 2.78 & 1 & 1.64 \\
\hline 12 & 4 & 11.11 & 2 & 3.28 \\
\hline 13 & 4 & 11.11 & 4 & 6.56 \\
\hline
\end{tabular}

\begin{tabular}{|c|c|c|c|c|}
\hline 14 & 6 & 16.67 & 15 & 24.59 \\
\hline 15 & 7 & 19.44 & 10 & 16.39 \\
\hline 16 & 5 & 13.89 & 16 & 26.23 \\
\hline 17 & 6 & 16.67 & 6 & 9.84 \\
\hline 18 & 0 & 0 & 4 & 6.56 \\
\hline 19 & 1 & 2.78 & 2 & 3.28 \\
\hline 20 & 0 & 0 & 1 & 1.64 \\
\hline 21 & 2 & 5.56 & 0 & 0 \\
\hline
\end{tabular}

Variation of practice of UP with gender and experience

The frequency distributions on the practice of UP showed different patterns of variation for the two gender groups (Table 5). In the female group, $67 \%$ of respondents had total coded marks within the narrow range between 14 and 16. In contrast, the total coded marks in the male group showed a wider distribution with the range between 12 and 17 in $89 \%$. Interestingly, the two respondents who had the maximum possible totals of coded marks were males. However, there was a higher percentage of lower performers (i.e. who had lower total coded marks such as 11, 12 and 13) among the male group as compared to the female group. Therefore, it can be concluded that there is greater room for improvement of practice of UP among the male anaesthetists than among their female counterparts.

Table 6: Frequency distributions of the total coded marks for practice of UP among respondents of different experience groups

\begin{tabular}{|c|c|c|c|c|c|c|}
\hline $\begin{array}{c}\text { Experi } \\
\text { ence }\end{array}$ & \multicolumn{2}{|c|}{$<6$ months } & \multicolumn{2}{|c|}{6 months -5 years } & \multicolumn{2}{|c|}{$>5$ years } \\
\hline $\begin{array}{c}\text { Total } \\
\text { coded } \\
\text { mark } \\
\text { obtain } \\
\text { ed }\end{array}$ & $\begin{array}{c}\text { No. } \\
\text { of } \\
\text { Res } \\
\text { pon } \\
\text { den } \\
\text { ts }\end{array}$ & $\begin{array}{c}\% \\
\text { in } \\
\text { the } \\
\text { Pop } \\
\text { ulat } \\
\text { ion }\end{array}$ & $\begin{array}{c}\text { No. of } \\
\text { Respon } \\
\text {-dents }\end{array}$ & $\begin{array}{c}\% \text { in the } \\
\text { Populatio } \\
\text { n }\end{array}$ & $\begin{array}{c}\text { No. of } \\
\text { Respon } \\
\text {-dents }\end{array}$ & $\begin{array}{c}\% \text { in } \\
\text { the } \\
\text { Popul } \\
\text { ation }\end{array}$ \\
\hline 11 & 0 & 0 & 1 & 1.64 & 1 & 1.75 \\
\hline 12 & 1 & 50 & 2 & 3.28 & 4 & 7.02 \\
\hline 13 & 1 & 50 & 4 & 6.56 & 3 & 5.26 \\
\hline 14 & 0 & 0 & 15 & 24.59 & 11 & 19.3 \\
\hline 15 & 0 & 0 & 10 & 16.39 & 10 & 17.54 \\
\hline 16 & 0 & 0 & 16 & 26.23 & 14 & 24.56 \\
\hline 17 & 0 & 0 & 6 & 9.84 & 5 & 8.77 \\
\hline 18 & 0 & 0 & 4 & 6.56 & 4 & 7.02 \\
\hline 19 & 0 & 0 & 2 & 3.28 & 3 & 5.26 \\
\hline 20 & 0 & 0 & 1 & 1.64 & 1 & 1.75 \\
\hline 21 & 0 & 0 & 0 & 0 & 1 & 1.75 \\
\hline
\end{tabular}


Table 6 shows the respective frequency distributions of the total coded marks for practice of UP for the three experience groups. However, a meaningful comparison can be made only between the second and the third group because the first group contained only two respondents. There was no substantial variation between second and third experience groups in terms of their practice of UP. In both groups, 60 $-70 \%$ of the respondents were within the total coded marks range between 14 and 16 out of the possible maximum of 21 . Both groups had approximately similar percentages of higher and lower performers. Therefore, it can be concluded that experience does not play a significant role in determining the practice of UP among the anaesthetists.

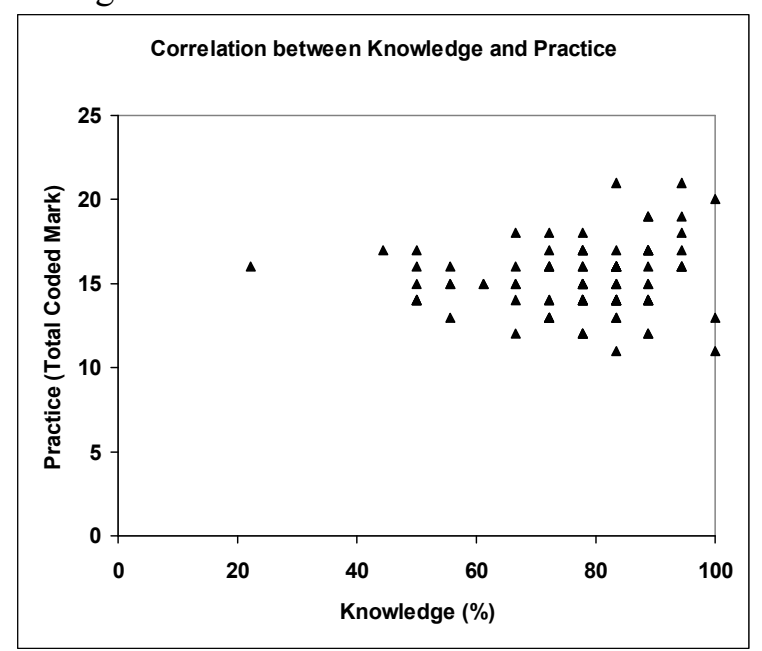

Figure 1: Relationship between knowledge and practice of UP among the respondents

\section{Relationship between knowledge and practice of UP}

The relationship between knowledge and practice of UP among the 97 respondents is shown in Fig. 1, which shows that there is no clear relationship between knowledge and practice of UP. Therefore, these results show that having knowledge about UP is no guarantee that the respondents put that knowledge in to practice. For example, the three respondents who had $100 \%$ knowledge had widely differing marks for their practice of UP. Similarly, within each group having similar marks for knowledge, there were widely-ranging marks for practice. Therefore, it can be concluded that there is no relationship between having prior knowledge on
UP and their practice. This again points out towards the fact that practice of UP is a personal trait, which is more influenced by the discipline of an anaesthetist rather than by his or her knowledge on UP. Although a person with no knowledge of UP cannot practice UP, having knowledge of UP is no guarantee that it will be put in to practice.

Table 7: Variation of respondents who were more

comfortable without gloves with gender and experience of the respondents

\begin{tabular}{|l|l|l|l|l|}
\hline & & No. more & \\
Gender & Experience & $\begin{array}{l}\text { No. of } \\
\text { Respondents }\end{array}$ & $\begin{array}{l}\text { comfortabl } \\
\text { e without } \\
\text { gloves }\end{array}$ & \% \\
\hline Male & $<6$ months & 1 & 1 & 100 \\
\hline & $\begin{array}{l}6 \text { months }-5 \\
\text { years }\end{array}$ & 14 & 8 & 57.14 \\
\hline & $>5$ years & 21 & 12 & 57.14 \\
\hline & $\begin{array}{l}\text { Sub- } \\
\text { total/Mean }\end{array}$ & 36 & 21 & 58.33 \\
\hline & $<6$ months & 1 & 1 & 100 \\
\hline & $\begin{array}{l}6 \text { months }-5 \\
\text { years }\end{array}$ & 24 & 9 & 37.50 \\
\hline & $>5$ years & 36 & 13 & 36.11 \\
\hline & $\begin{array}{l}\text { Sub- } \\
\text { total/Mean }\end{array}$ & 61 & 24 & 37.70 \\
\hline & Total/Mean & 97 & 45 & 46.39 \\
\hline
\end{tabular}

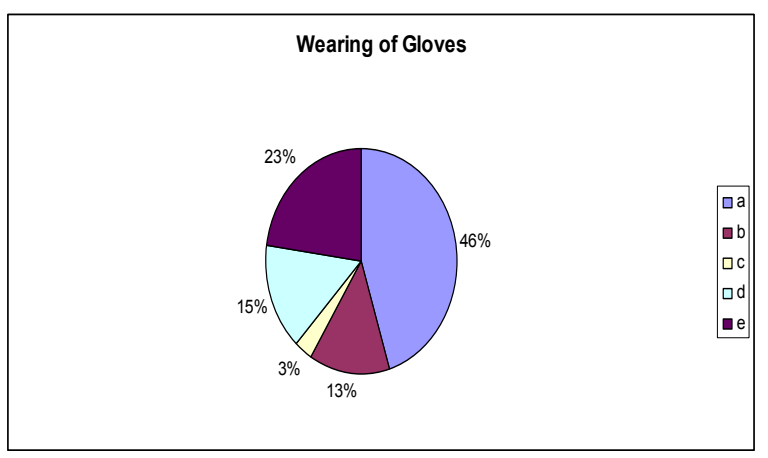

Figure 2: Wearing of gloves and reasons for not wearing them at the OT among the respondents. a - Comfortable to work without gloves; b - Non-availability of clean gloves of appropriate size;

c- Allergy;

$\mathrm{d}$ - Wear gloves all the time;

$\mathrm{e}-$ Other reasons. 
The practice of wearing gloves and reasons for not wearing

Figure 2 shows the responses to the specific question in the questionnaire on wearing of gloves at the OT and reasons for not wearing. It was revealed that only $15 \%$ of the respondents wore gloves all the time in the OT. $46 \%$ of the respondents felt more comfortable working without gloves, despite clean gloves of appropriate size being available. However, this preference was not related to experience (Table 7) as the two major experience groups (i.e. 6 months -5 yrs and above $5 \mathrm{yrs}$ ) did not differ in the percentage of respondents being more comfortable without gloves. Interestingly, a significantly higher percentage of male respondents (i.e. $58 \%$ ) were more comfortable without gloves than their female counterparts $(38 \%)$. Only $13 \%$ of respondents cited nonavailability of gloves as a reason for not wearing them. Based on these responses, it can be concluded that a substantial improvement is needed in this practice among the anaesthetists.

Further analysis of individual questions revealed that only 72 respondents $(74 \%$ of the study population) had completed the three dose vaccine series against hepatitis $\mathrm{B}$, and only $49 \%$ of them had confirmed their level of protection against hepatitis B (post vaccination antibody levels) in the event of an accidental exposure. This shows room for further improvement. It was also noted that only $24 \%$ of the study population had had any form of education or awareness programmes regarding UP during the last three years.
Based on the results of this study, I would like to make the following recommendations:

1) The National Guidelines on Standard Precautions should be widely available for easy reference at operating theatres and the anaesthetists should be made aware of such guidelines.

2) Disposable gloves of different sizes should be made available for anaesthetists in the operating theatres;

3) Knowledge and awareness on the importance of practising UP, should be improved during the monthly Morbidity and Mortality Meetings as well as during routine theatre sessions;

4) The hepatitis B vaccine and post vaccine anti body test should be provided free of charge for all the anaesthetists, and it should be made mandatory to have adequate coverage prior to taking over duties as an anaesthetist.

\section{References}

1. Hospital infection control Manual for 2005 and 2006 prepared by the Sri Lankan College of Microbiologists. J Hosp Infect. 54(1): 68-73. (2003)

2. A survey of doctors' and nurses' knowledge, attitudes and compliance with infection control guidelines in Birmingham teaching hospitals. $\underline{\mathbf{J}}$ Med Assoc Thai. 78 Suppl 2: S112-7. (1995).

3. Health care workers' knowledge on HIV and AIDS: universal precautions and attitude towards PLWHA in Benin-City, Nigeria. Niger J Clin Pract. 8(2): 74-82. (2005).

4. Centres for Disease Control (CDC) guidelines on UP.

5. SLCM National Guidelines / Standard Precautions

\section{Recommendations}




\section{Appendix I: Questionnaire used in the study}

Anaesthetists are a group of doctors who are at a higher occupational risk of transmitting blood borne infections. As part of my MD Anaesthesiology training I am doing a study on knowledge and practice of Universal Precautions in this group. I intend giving recommendations to minimize this risk.

I would be grateful if you could provide your honest responses to all the questions. Confidentiality would be maintained.

(Pleas mark a $\square$ in the appropriate cage )

1. How long have you been working as an Anaesthetist?
(a) Less than 6 Months
(b) 6- Months - 5 Years
(c) More than 5 Years

2. Gender
(a) Male
(b) Female

3. Do you wear gloves prior to IV cannulation?
(a) Yes always
(b) Most of the time, not on a regular basis
(c) Never
(d) Only if it is a high risk patient

4. Any reason for not wearing gloves regularly at the OT
(a) Comfortable to work without them
(b) Non availability of clean gloves of appropriate sizes
(c) Allergy
(d) Wear gloves all the time.
(e) Other

5. Do you wear a plastic/water resistant apron when you handle patients with multiple bleeding wounds?

(Ex. Trauma victims )
(a) Yes always
(b) Never
(c) Only if it is a high risk patient
(d) Not handled such patients

6. Do you wash hands after removal of gloves at the end of a procedure?
(a) Yes
(b) No

7. Do you locate the sharp bin and get it easily accessible prior to IV cannulation?
(a) Yes
(b) No

8. How do you discard a contaminated needle with a syringe

(a) Keep separately on a open tray to be discarded at the end of the day

(b) Recap needle without touching and discard to the sharp bin 
(c) Drop both needle and syringe to the sharp bin without recapping

(d) Remove needle and drop it to the sharp bin, and the syringe to the plastic waste bin

9. Methods in which an Anaesthetist could get Hepatitis B or HIV transmitted during work.

$$
\text { Yes No }
$$

10. Splashes of infected body fluids on eyes or mucous membranes

(a) Touching of infected persons

(b) Blood spalash on intact skin

(c) Accidental pricks with contaminated needles

(d) Blood / Body Fluid spill on feet with active eczema

11. If the accidental injury occurs through the glove will it reduce the risk?
(a) Yes
(b) No

12. Universal precautions and guidelines are practiced to reduce the transmission of blood borne infections. They include:
(a) Wearing of sterile gloves all the time.
(b) Hand washing after handling each patient
(c) Wash hands after removal of gloves at the end of a spinal anaesthetic
(d) Use personal protective equipment during high risk procedures (Ex. Masks, Goggles, aprons, gowns.)
(e) Wear protective gloves only if you have an open wound
(f) Change gloves every time when it gets contaminated even if you are handing the same patient.

13. Ideal location of a sharp bin in the operating theatre
(a) At a corner where less people will move around
(b) Close as practical to the area where sharp is used
(c) Any accessible area

14. In the event of an accidental contaminated needle prick / splash of body fluid the recommended steps to be followed
(a) Encourage bleeding from wound
(b) Wash wound with soap and water or irrigate mucous membrane with lot of water / saline
(c) Clean with betadine or ethyl alcohol (spirits) prior to washing.
(d) Inform infection control team through OT Sister and get relevant 
advice.

(e) Test the known source for HBs Ag, anti HCV or HIV antibody with the consent.

15. Have you completed the three dose vaccine series against Hepatitis B?
(a) Yes
(b) No

16. Have you checked your post vaccination anti HBs antibody levels?
(a) Yes
(b) No

17. Have you attended any lecture / workshop, on prevention and risk of transmission of blood borne infections among health care workers during the last three years?
(a) Yes
(b) No

\section{Appendix II: Coded marks for questions on practice of Universal Precautions}

Question 3:
a. 4
b. 3
c. 1
d. 2

Here, it can be seen that that the best practice gets the highest coded mark (i.e. 4) while the worst practice (i.e. 1) gets the lowest coded mark.

Question 5:
a. 3
b. 1
c. 2
d. 0

Here, response $\mathrm{d}$ is given 0 as this question is not applicable to respondents giving answer $\mathrm{d}$.

Questions 6, 7, 14, 15 and 16:
a. 2
b. 1

Question 8:
a. 1
b. 3
c. 4
d. 2 